\title{
Demand and Supply of Public Transport- The Problem of Cause and Effect
}

\author{
Johan Holmgren \\ Linköping University Post Print
}

Tweet

N.B.: When citing this work, cite the original article.

Original Publication:

Johan Holmgren, Demand and Supply of Public Transport- The Problem of Cause and Effect, 2005, Competition and Ownership in Land Passenger Transport: selected refereed papers from the 8th International Conference (Thredbo 8), Rio de Janeiro, September 2003, 405-421.

Copyright: Elsevier

http://www.elsevier.com/

Postprint available at: Linköping University Electronic Press

http://urn.kb.se/resolve?urn=urn:nbn:se:liu:diva-31404 


\title{
DEMAND AND SUPPLY OF PUBLIC TRANSPORT - THE PROBLEM OF CAUSE AND EFFECT
}

\author{
Johan Holmgren \\ Department of Management and Economics \\ Linköping University, Sweden
}

\section{INTRODUCTION}

In many demand studies concerning public transportation, vehicle-kilometres turn out to be one of the most important explanatory variables. Generally, high elasticities of travel demand with respect to vehicle-kilometres are reported, in some cases above one (for example Webster and Bly, 1980; Holmgren, 2001; Dargay and Hanly, 2002).

Figure 1 shows vehicle-kilometres per capita supplied against number of trips ${ }^{1}$ made per capita by bus in urban areas. ${ }^{2}$ The data is from the 24 Swedish counties, each square represents per capita averages over the period 1986 to 2001. The correlation between vehiclekilometres and patronage is 0.97 , which indicates a strong linear relationship.

The observation in the upper right-hand corner is Stockholm, which stands out against all other counties. Stockholm is the only county in Sweden where there is an undergroundsystem; this, together with the county's unique traffic situation, might explain the difference.

\footnotetext{
${ }^{1}$ Greater part of the data consists of bus-kilometres and trips made by bus, although in Stockholm a substantial part originates from the underground-system. In Göteborg, and Östergötland a small amount of rail traffic is included. In the rest of the paper this is referred to as vehicle-kilometres and trips made (patronage).

${ }^{2}$ In the rest of the paper vehicle-kilometres and trips made (patronage) refers to per capita figures.
} 


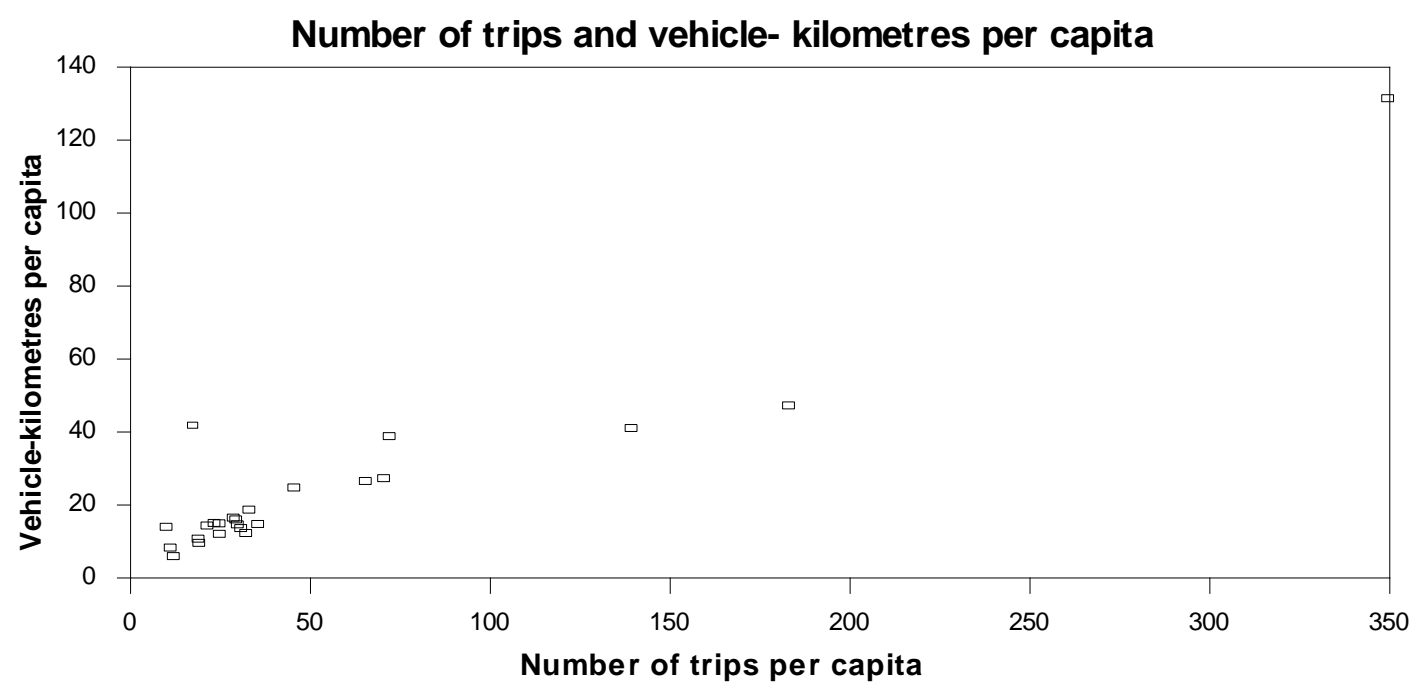

Source: SLTF and Statistics Sweden.

Figure 1: Per capita patronage against vehicle-kilometres per capita in averages for each county

It seems obvious that there is a relationship between the variables. The use of vehiclekilometres as one of the explanatory variables in travel demand models is therefore logical (to be discussed below) but not without problems. It brings up yet another version of the question of 'the chicken or the egg'. Which came first? The strong correlation between the variables and the significance of vehicle-kilometres in demand studies says nothing about the causal relationship. Naturally, public transport patronage is affected by other factors than vehiclekilometres. Prices, car ownership and institutional factors are also important. During the observed time-period real fares has increased (SLTF, 2002) as well as car-ownership, and some important institutional changes have occurred. Since 1989 the market for public transport is open to competitive tendering. However, these changes will not be studied in this paper. For more on institutional relations and changes in the Swedish public transport market see Jansson and Wallin (1991) and more recently SLTF-report (2002).

\section{Purpose and plan of the paper}

The purpose of this paper is to determine the nature of the causal effect between public transport patronage and vehicle-kilometres. To achieve this, the concept of Granger-causality is used. (Granger-causality is a definition of a cause and effect relationship between variables that utilises the time-lag between the cause and the effect. The concept will be further described and discussed later.) To the author's knowledge no similar studies of cause and effect in public transport have been made.

First the development of patronage and vehicle-kilometres in Sweden is described. Next, the rationale for using vehicle-kilometres in travel demand-models will be explained. Then the concept of causality and the tests of cause and effect will be discussed. The last part discusses estimation and interpretation of the results using the data from Sweden. 


\section{THE DATA}

The study uses annual data from the period of 1986 to 2001. The data concerning patronage and vehicle-kilometres is supplied by The Swedish Public Transport Association (Svenska lokaltrafikföreningen, SLTF) to which local transport authorities report several key statistics. Before 1986 the data is not reported in the same way and it is not possible to convert the series to be compatible. In the study per capita data is used to prevent demographic changes influencing the results. Population statistics from Swedish urban areas were obtained from Statistics Sweden (SCB).

During this period the total amount of trips made in urban areas in Sweden rose as well as the total number of vehicle-kilometres. Patronage rose from 132 to 153 trips per person, an increase of 16 per cent, while vehicle-kilometres rose from 48 to $61 \mathrm{~km}$ per person (27 per cent).

The upward trend that seems to be present in both variables does not represent the general development. From table 1 it is clear that the rise in the number of trips made originates from Stockholm, Västernorrland and Blekinge. Since such a large part of the total amount of trips made in urban areas is made in Stockholm, this is enough for the aggregated numbers to show an upward trend from 1997.

Table 1. Per centage change in trips made per capita (patronage) and vehicle-kilometres per capita supplied (Vkm) in each county from 1986 to 2000.

\begin{tabular}{|l|r|l|r|r|}
\hline County & Patronage Vkm & County & Patronage & Vkm \\
\hline Stockholm & 8.4 & 4.3 Älvsborg & -29.1 & -10.5 \\
\hline Uppsala & -49 & -29.6 Skaraborg & -38.7 & -21.4 \\
\hline Sörmland & -29.4 & 2.1 Värmland & -34.3 & -14 \\
\hline Östergötland & -51.4 & -0.8 Örebro & -39.1 & -6.3 \\
\hline Jönköping & -27.1 & -6.2 Västmanland & -39.8 & 18.8 \\
\hline Kronoberg & -20.2 & 7.8 Dalarna & -52 & -7.1 \\
\hline Kalmar & -79.3 & -36 Gävleborg & -33.8 & \\
\hline Gotland & -44.7 & -6.9 Västernorrland & 25.8 & 8 \\
\hline Blekinge & 5.2 & 10.3 Jämtland & -5.3 & 29.5 \\
\hline Malmö & -32.1 & 18.2 Västerbotten & -16.4 & -16.2 \\
\hline Göteborg/Bohus & -19.8 & -29.3 Norrbotten & -39 & -1.9 \\
\hline
\end{tabular}

Source: SLTF. * = data missing from $1997 * *$ = data missing from 1994

Underneath these aggregates the individual counties display a great amount of variation. Table 1 shows the changes (per cent) in patronage and vehicle-kilometres in each county.

In all counties except three (Stockholm, Västernorrland and Blekinge), patronage fell between 1986 and 2000. Stockholm accounts for a large part of the total number of trips made in Sweden (69\% in 2000) and a large part of the total amount of vehicle-kilometres (67\%). This is the reason for the increase in the total amounts. In Västernorrland, which has had the most favourable development, patronage rose 25.8 per cent during the period, while in the county of Kalmar patronage dropped 79 per cent. The supply of vehicle-kilometres was increased by 30 per cent in Jämtland, while it was lowered by 36 per cent in Kalmar. 
Figure 2 shows the development of the variables during the same period for the counties that include large urban areas (defined by SLTF) when Stockholm, Malmö and Göteborg/Bohuslän are excluded (Uppsala, Östergötland, Jönköping, Örebro, Västmanland and Västerbotten). In this case we can see that the number of trips fell from 70 to 40 trips per person ( -43 per cent) and vehicle-kilometres fell from 26 to $24 \mathrm{~km}$ per person ( -7.7 per cent). It is clear that in these counties the level of the variables are much lower than in Stockholm and falling while the levels in Stockholm are increasing.

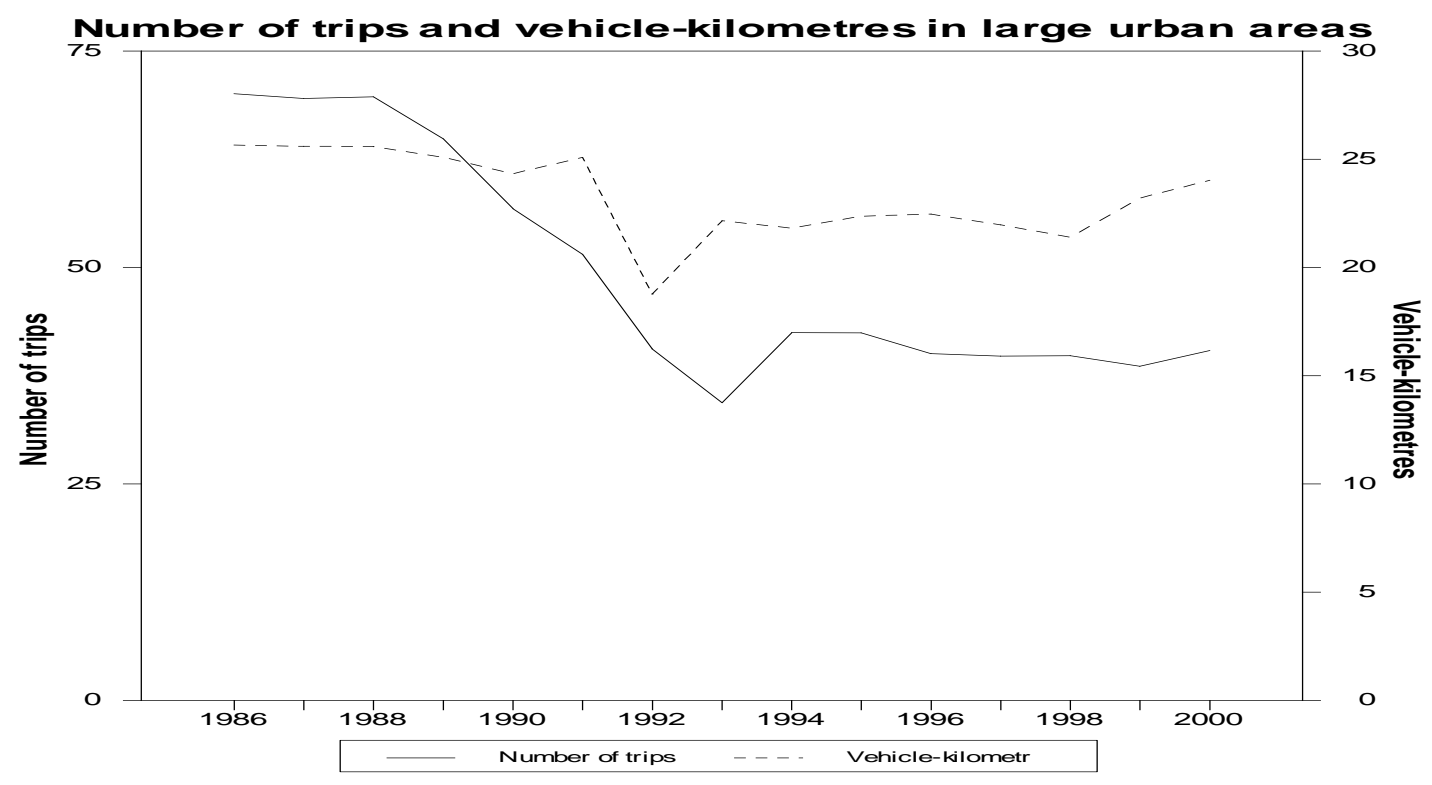

Source: SLTF and Statistics Sweden.

Figure 2: Development of the number of trips (per capita) made and vehiclekilometres (per capita) supplied in the larger urban areas (except for Stockholm, Malmö and Göteborg/bohus) in Sweden from 1986 to 2000

Figure 3 shows the development of patronage and vehicle-kilometres in small urban areas. The number of trips fell from 33 to 19 ( -42 per cent) and vehicle-kilometres fell from 16 to 15 ( -6 per cent). 


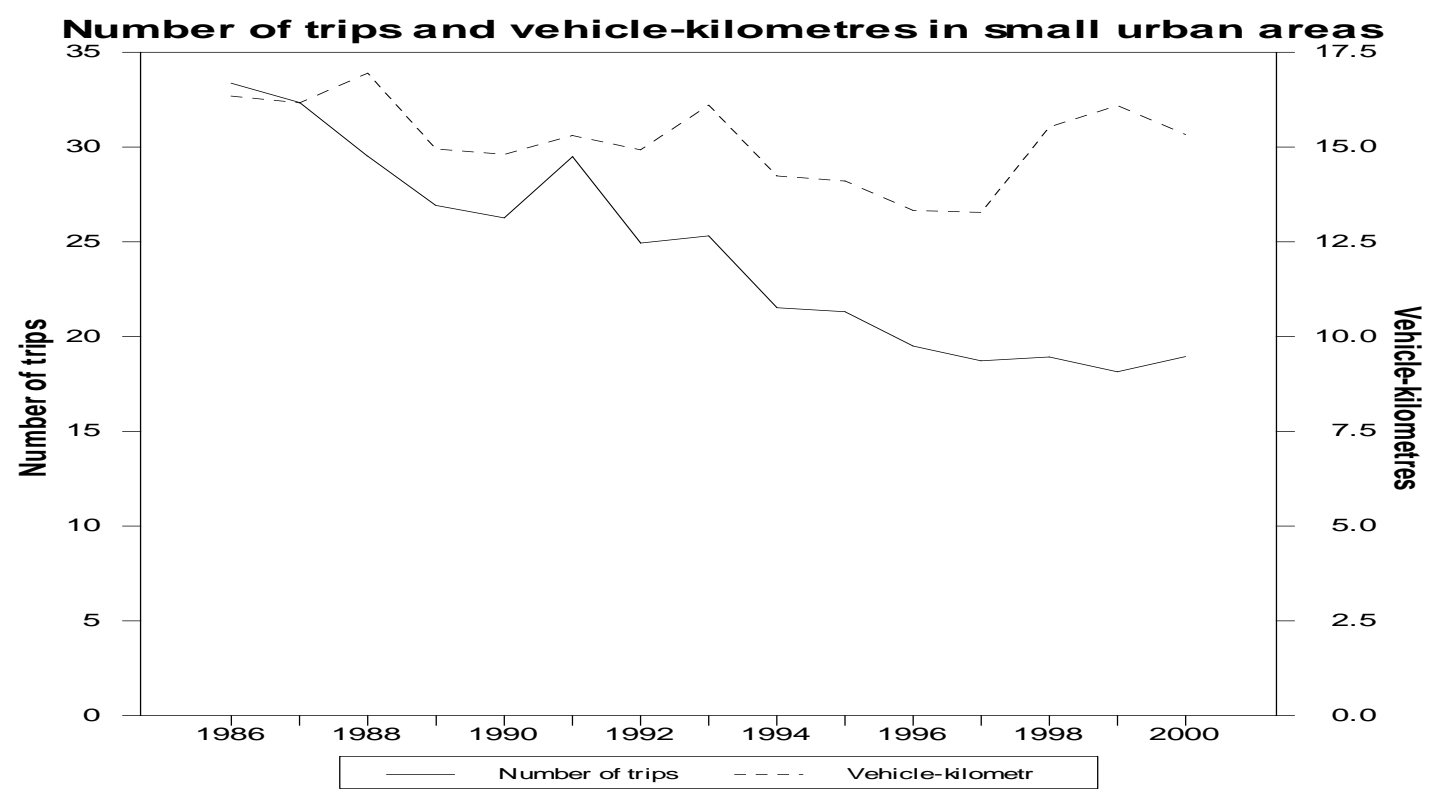

Source: SLTF and Statistics Sweden.

Figure 3. Development of the number of trips (per capita) made and vehiclekilometres (per capita) supplied in smaller urban areas in Sweden from 1986 to 2000

From the figures it is apparent that the level of supply and trips made per capita varies extensively between large and small urban areas. This is no surprise; the competition from other modes of transport is more extensive in the smaller urban areas. Car ownership is higher in these areas and walking and cycling are often much more competitive alternatives to public transport in small urban areas than in large.

The fall in patronage was large in both small and large urban areas (Stockholm excluded) but the fall in vehicle-kilometres was relatively small in the counties without large urban areas.

The figures show that the number of trips and vehicle-kilometres supplied follow each other, and the picture presented in figure 1 seems to hold.

\section{VEHICLE-KILOMETRES AND DEMAND-MODELS}

Vehicle-kilometres is often referred to as a measure of service quality. This practice is however somewhat misleading, the quality of a transport service is a very complex matter and includes safety, comfort and reliability etc. whereas vehicle-kilometres focuses on the time aspect alone. To separate the time aspect from other quality variables it is useful to move into the realm of generalised cost.

Generalised cost (GC) is the total cost of travel including the value of the time that is used during the trip. GC for a journey can then be written: 
$G C=p+a_{1} F T+a_{2} W T+a_{3} T T$

Where:

$\mathrm{p}=$ monetary cost of making the trip.

FT $=$ the feeder time - for public transportation, the time it takes to walk to the nearest stop.

$\mathrm{WT}=$ waiting time. It includes so called hidden waiting time occurring when a trip is made earlier or later then the preferred time as a result of the schedule not being perfect for the individual's needs.

$\mathrm{TT}=$ travel time - the time actually spent travelling.

$a_{1}-a_{3}=$ the value of the different types of time described above.

The value of the different types of time varies between different modes of transport and between transport systems. In this framework the quality of a specific mode affects the different value of time coefficients $\left(a_{1}-a_{3}\right)$, while vehicle-kilometres affects the time required for a trip (FT, WT, TT).

Using the notation of Webster and Bly (1980), the total number of vehicle-kilometres (vkm) that is being run in can be written:

$v k m=\sum_{i=1}^{r} \sum_{j} n_{i j} v_{i j} t_{j}$

Where:

$\mathrm{r}=$ number of routes.

$\mathrm{n}_{\mathrm{ij}}=$ number of vehicles run on route $\mathrm{i}$ during period $\mathrm{j}$.

$\mathrm{V}_{\mathrm{ij}}=$ effective speed.

$t_{j}=$ the length of period $\mathrm{j}$.

If the length of route $\mathrm{i}$ is $\mathrm{l}_{\mathrm{i}}$ the total frequency $\mathrm{F}_{\mathrm{ij}}$ on that route during period $\mathrm{j}$ is:

$F_{i j}=n_{i j}\left[\frac{v_{i j}}{l_{i}}\right]$

and therefore: 
$v k m=\sum_{i} l_{i} \sum_{j} F_{i j} t_{j}$

An observed increase in vehicle-kilometres produced can therefore come from different sources. The length of one or more of the routes in the system might have increased. If this is achieved by expanding the area of operation the effect is a lower generalised cost, assuming that the expansion is not accompanied by a decrease in frequency (which implies a larger fleet). The picture is more complicated if the increase occurs without expanding the area of operation. In this case the route density increases, resulting in a lower feeder time and hence generalised cost, but even if maintained frequency is assumed there is a trade off situation. Increasing route density within the same area often means less direct routes, which increases the travel time and therefore increases generalised cost. The increase in route length could also be accomplished through an increase in the number of routes. Again, assuming unchanged frequency this lowers generalised cost.

Vehicle-kilometres can also be increased through higher frequency. Assuming unchanged speed and total route length this results in a lower generalised cost through shorter waiting times.

The third way of producing more vehicle-kilometres is to increase the length of time the existing fleet is utilised. Since trips could than be made earlier and/or later in the day, hidden waiting time is decreased and hence generalised cost as well.

This shows that the number of vehicle-kilometres produced is closely related to generalised cost. Most frequently, increased production of vehicle-kilometres is accompanied by increased fleet size and/or higher utilisation of the existing fleet, and thus lower generalised cost.

Next the focus will be on the demand function. A direct demand model for a specific transport mode can be written:

$D=f\left(G C_{1}, G C_{2}, \ldots, G C_{n}, X\right)$

Where:

$\mathrm{GCs}=$ generalised cost for transport mode $\mathrm{s}$ of the $\mathrm{n}$ transport modes.

$\mathrm{X}=\mathrm{a}$ number of socio-economic variables such as income, employment and housing situation.

In practice, the time components of the GC are difficult to measure therefore demand is written:

$D=g\left(p_{1}, p_{2}, \ldots, p_{n}, v k m, X\right)$

$\mathrm{p}_{\mathrm{s}}=$ monetary cost of making the trip with mode $\mathrm{s}$. 
$\mathrm{vkm}=$ vehicle-kilometres.

In this demand model it is assumed that $\mathrm{a}_{1 \mathrm{i}}, \mathrm{a}_{2 \mathrm{i}}$, and $\mathrm{a}_{3 \mathrm{i}}$ are held constant for all $\mathrm{i}$. Also assumed in (6) is that the time used for a specific trip with modes other than public transportation does not change. These assumptions are reasonable if the level of congestion and the infrastructure is unchanged. If not, measures of such changes can be included in X.

To sum up, it has been shown that it is reasonable to include vehicle-kilometres when estimating a demand function. However, it is also plausible to think that decision-makers observe a change in travel behaviour and therefore change the supply of service. The "vicious circle' of public transportation is often mentioned. In this circle declining supply of vehiclekilometres is followed by declining patronage, leading to yet another decrease in service supply and so on, or declining patronage is followed by declining service supply leading to further decrease in patronage, and so on. For the description of the circle to be legitimate vehicle-kilometres must be a function of demand, hence the causal relationship must run both ways. This relationship can be written:

$v k m=h(D, C, Y)$

Where:

$\mathrm{C}=$ cost of input factors.

$\mathrm{Y}=\mathrm{a}$ number of policy variables and producer specific variables.

$\mathrm{Y}$ might include such things as the producer's financial status and inclination to prioritise public transport (the producer being a public authority in Sweden). The fact that demand appears in (7) raises the problem of simultaneous bias.

To shed light on this causal relationship we later turn to the concept of Granger-causality.

\section{CAUSE AND EFFECT}

Philosophers have discussed extensively the definition of cause and effect relations. Sometimes cause is seen to be necessary for the effect. If this were the case the relation between patronage and vehicle-kilometres would not be unclear. Patronage is clearly impossible without production of vehicle-kilometres while the opposite is not true. Therefore, according to that definition, vehicle-kilometres cause patronage and not the other way around.

David Hume used a different definition. According to him, what is observed when something is classified as a cause and effect relation is: 1) the cause occurs before the effect, 2) cause and effect are located closely in space and 3 ) it seems that the cause is always followed by the 
effect. According to this definition the connection between cause and effect is empirical and not logical. Hence the cause does not need to be necessary for the effect.

For an event to occur a complex set of conditions needs to be present and it is therefore too complicated to point to a single cause for an effect. John Mackie (1974) produced the following definition: a cause is an insufficient but necessary part of an unnecessary but sufficient condition.

Causality is a problematic concept, especially in the social sciences. In the natural sciences and medicine one might use controlled experiments to examine the effect of a change in one variable thought to affect the subject of study while keeping other things unchanged. This is generally not possible in studies of social phenomena. Instead one has to rely on theory to dictate the nature of the relationship between variables. Sometimes, as is the case with patronage and vehicle-kilometres, theory is not sufficient to determine the direction of the relationship.

\section{Granger-causality}

In econometrics Clive Granger developed a concept of causality that is empirically testable. Christopher Sims has developed a somewhat different method based on the same concept (Granger, 1969; Sims, 1972). These tests rely on the observed difference in time between cause and effect. The rationale behind the tests is that if a variable $\mathrm{X}$ causes another variable $\mathrm{Y}$, a forecast of $\mathrm{Y}$ using past values $\mathrm{Y}$ and $\mathrm{X}$ outperforms a forecast using only past values of Y. That is if:

$\sigma^{2}(\mathrm{Y} \mid \mathrm{U})<\sigma^{2}(\mathrm{Y} \mid \mathrm{U}-\mathrm{X})$

Where $\mathrm{U}$ represents all available information (the series $\mathrm{Y}$ and $\mathrm{X}$ in the two-variable case) and $\mathrm{U}-\mathrm{X}$ represents the same information with the exception of the variable $\mathrm{X}$.

According to Granger's definitions a feedback relationship exists between Y and X if:

$\sigma^{2}(\mathrm{Y} \mid \mathrm{U})<\sigma^{2}(\mathrm{Y} \mid \mathrm{U}-\mathrm{X})$

$\sigma^{2}(X \mid U)<\sigma^{2}(X \mid U-Y)$

To test for this relationship in the two-variable case the following model is used:

$$
\begin{aligned}
& Y_{t}=\sum_{j=1}^{m} a_{j} X_{t-j}+\sum_{j=1}^{m} b_{j} Y_{t-j}+\varepsilon_{t} \\
& X_{t}=\sum_{j=1}^{m} c_{j} X_{t-j}+\sum_{j=1}^{m} d_{j} Y_{t-j}+\varepsilon^{\prime}{ }_{t}
\end{aligned}
$$

In this case four possibilities exist: 


\section{X causes $\mathrm{Y}$}

2. $Y$ causes $X$

3. $\mathrm{X}$ and $\mathrm{Y}$ cause each other (a feedback exists)

4. There is no causal relationship between the variables

Initially the first possibility is tested with an F-test of equation (8) where $\mathrm{H}_{0}: \mathrm{a}_{\mathrm{j}}=0, \forall \mathrm{j}$ and $\mathrm{H}_{1}$ : at least one $\mathrm{a}_{\mathrm{j}} \neq 0$. If $\mathrm{H}_{0}$ is rejected $\mathrm{X}$ is said to cause $\mathrm{Y}$. The procedure is repeated for equation (9) with $\mathrm{H}_{0}$ : $\mathrm{d}_{\mathrm{j}}=0, \forall \mathrm{j}$ and $\mathrm{H}_{1}$ : at least one $\mathrm{d}_{\mathrm{j}} \neq 0$. If $\mathrm{H}_{0}$ is rejected for both equations $\mathrm{X}$ and $\mathrm{Y}$ is said to cause each other.

The test outlined above requires that both $\mathrm{X}$ and $\mathrm{Y}$ are stationary otherwise estimated relationships could be spurious. Sometimes the test is sensitive to the choice of lag-length.

\section{Granger-causality and panel-data}

In a panel-data setting the material might show greater heterogeneity, this must be considered. When causality is investigated one must determine whether or not one variable causes the other for some or all individuals and whether or not the relationship is the same for all individuals. When testing whether or not vehicle-kilometres cause patronage, four types of relationships can be identified based on Hurlin and Venet (2001):

1. Homogenous non-causality (HNC). In the case of homogenous non-causality vehiclekilometres do not cause patronage in any county. Based on theory this seems highly unlikely but the hypothesis must be investigated.

2. Homogenous causality (HC). Homogenous causality means that vehicle-kilometres cause patronage and that the relationship is identical in all counties. This means that a change in the supply of vehicle-kilometres causes the same change in the number of trips made in all counties.

3. Heterogeneous causality (HEC). If vehicle-kilometres cause patronage in all counties but the effect varies between them the situation is identified as heterogeneous causality. That is, changes in supply cause changes in patronage in every county but the size (perhaps even the direction) of the effect is not the same in all counties.

4. Heterogeneous non-causality (HENC). The last possibility is that vehicle-kilometres cause patronage in some counties but not in all of them. Hence there are counties where supply does cause demand but there is at least one where this is not the case.

Since the same classifications apply when the effect of patronage on vehicle-kilometres is considered there are sixteen possible relationships between vehicle-kilometres and the number of trips made.

The test-procedure outlined by Hurlin and Venet (2001) involves testing the above hypothesises in the following order: $\mathrm{HNC}, \mathrm{HC}$ and HENC. The procedure stops if one hypothesis is accepted and if all is rejected the conclusion is that there is heterogeneous causality in the panel.

The starting-point of the analysis is the general model: 
$Y_{i, t}=\alpha_{i}+\sum_{k=1}^{p} \gamma_{k} Y_{i, t-k}+\sum_{k=1}^{p} \beta_{i, k} X_{i, t-k}+v_{i, t}$

If the relationship between $\mathrm{X}$ and $\mathrm{Y}$ is characterised by homogenous non-causality $\mathrm{X}$ does not cause $Y$ for any of the individuals in the panel. In terms of (10) the test for this hypothesis is stated as:

$\mathrm{H}_{0}: \beta_{\mathrm{ik}}=0$ for all $\mathrm{i}$ and $\mathrm{k}$

$\mathrm{H}_{1}$ : there exists at least one $\beta_{\mathrm{ik}} \neq 0$

Under the null hypothesis all $\beta_{\mathrm{ik}}$ :s are zero for all individuals $\mathrm{i}$ in the panel. The HNChypothesis is tested by the following test statistic:

$$
F_{H N C}=\frac{\left(R S S_{2}-R S S_{1}\right) /(N p)}{R S S_{1} /[N T-N p-N-p]}
$$

Where $\mathrm{RSS}_{1}$ is the sum of squared residuals obtained from (10) and $\mathrm{RSS}_{2}$ is the restricted sum of squares under $\mathrm{H}_{0}$.

If homogenous causality occurs the $\beta_{\mathrm{k}}$ :s are different from zero and they take the same value for all individuals in the panel. This means that $\mathrm{X}$ cause $\mathrm{Y}$ and that the effect is the same for all individuals. A test for the $\mathrm{HC}$ hypothesis can be stated as:

$\mathrm{H}_{0}: \beta_{\mathrm{ik}}=\beta_{\mathrm{k}}$ for all $\mathrm{i}$

$\mathrm{H}_{1}$ : there exists at least one $\beta_{\mathrm{ik}} \neq \beta_{\mathrm{jk}}$ when $\mathrm{i} \neq \mathrm{j}$

The test statistic for the HC hypothesis is:

$F_{H C}=\frac{\left(R S S_{3}-R S S_{1}\right) /[p(N-1)]}{R S S_{1} /[N T-N p-N-p]}$

Where $\mathrm{RSS}_{1}$ is the same as above and $\mathrm{RSS}_{3}$ is the restricted sum of squares under $\mathrm{H}_{0}$.

In the case of heterogeneous non-causality $\mathrm{X}$ cause $\mathrm{Y}$ for some individuals but there is at least one individual for which $\mathrm{X}$ does not cause $\mathrm{Y}$. If this is the case the $\beta_{\mathrm{ik}}$ :s is zero for at least one i. The test is formally stated:

$\mathrm{H}_{0}$ : there exists at least one and at most $\mathrm{N}-1 \mathrm{i}$ where $\beta_{\mathrm{ik}}=0$ for all $\mathrm{k}$

$\mathrm{H}_{1}: \beta_{\mathrm{ik}} \neq 0$ for all $\mathrm{i}$ and $\mathrm{k}$

This test is performed in two steps. First the existence of causality is tested for each individual separately. The test statistic for each individual is: 


$$
F_{\text {henc }}^{i}=\frac{\left(R S S_{2 i}-R S S_{1}\right)}{R S S_{1} /[N T-N P-N-p]}
$$

where $\mathrm{RSS}_{2 \mathrm{i}}$ is the residual sum of squares under the hypothesis that $\beta_{\mathrm{ik}}=0$ for all $\mathrm{k}$. Thereafter the following test statistic is constructed:

$F_{H E N C}=\frac{\left(R S S_{4}-R S S_{1}\right) /\left(n_{n c} p\right)}{R S S_{1} /[N T-N p-N-p]}$

where $\mathrm{RSS}_{4}$ is the sum of squares under the hypothesis that for all $\mathrm{i}$ that were not significant according to the individual tests $\beta_{\mathrm{ik}}=0$ for all $\mathrm{k}$.

Heterogeneous causality is when $\mathrm{X}$ cause $\mathrm{Y}$ for all individuals but the process is not the same for all individuals. If this is the case the $\beta$ :s are not zero and they differ across individuals. HEC is concluded if the null hypothesis is rejected in all tests described above.

\section{ESTIMATION AND RESULTS}

As mentioned above, the causality test requires that the variables are stationary. Unlike the single series case, panel-data estimations are consistent when the number of individuals and periods tend to infinity (Baltiagi, 2001). Since this is not the case in this study the question of stationarity needs to be investigated further. Table 1 show that there have been considerable changes during the period in question. Visual inspection of the individual series gives further strength to the suspicion of them being non-stationary. Formal testing of single series is often performed by a Dickey-Fuller test. Testing the entire panel increases the power of the test. Many tests have been developed for panel data, and Banerjee (1999), Maddala and Wu (1999) and Baltiagi (2001) provide overviews and comparison of the tests. In this study the test developed by Levin and Lin (1993) is used due to ease of computation.3 The conclusion is that vehicle-kilometres per capita is stationary and that per capita patronage is trendstationary. The later therefore becomes stationary once the trend has been removed.

The presence of a deterministic trend could be due to the development of car ownership. During the period studied car possession rose in all counties, providing more and more competition to public transport when it comes to mode choice. Car ownership has proven to be an important determinant of public transport patronage (Holmgren, 2001; Dargay and Hanly, 2002). Therefore, the trend might be a proxy for the rising number of cars available to potential public transport users.

In the model below patronage refers to per capita patronage after removal of the trend.

\footnotetext{
3 Peter Pedroni has been helpful in providing the program used to test whether or not the series are stationary. For more information see Pedroni (1999).
} 


\section{Granger-causality in Sweden}

The models to be estimated are:

$$
\begin{aligned}
& P_{i, t}=\alpha_{i}+\sum_{K=1}^{p} \gamma_{k} P_{i, t-k}+\sum_{k=1}^{p} \beta_{i, t-k} V K M_{i, t-k}+\varepsilon_{i, t} \\
& V K M_{i, t}=\theta_{i}+\sum_{k=1}^{p} \lambda_{k} V K M_{i, t-k}+\sum_{k=1}^{p} \eta_{i, t-k} P_{i, t-k}+\delta_{i, t}
\end{aligned}
$$

Where:

$\mathrm{P}_{\mathrm{it}}=$ number of trips made in the $\mathrm{i}$ :th county year $\mathrm{t}$.

$\mathrm{VKM}_{\mathrm{it}}=$ vehicle-kilometres provided in the $\mathrm{i}$ : th county year $\mathrm{t}$.

Estimation of dynamic models in the panel-data setting is somewhat problematic since the lagged dependent variable is correlated with the error term. This leads to biased results. In absence of autocorrelation the estimation is consistent when the number of time-periods tends toward infinity. Since the number of observations over time is rather small in this study the problem remains. To avoid this problem estimation with instrument variables is used. For more information on estimation of dynamic panel data models see Baltiagi (2001) and Greene (2000).

The results from granger-causality tests may depend on the number of lags included in the model. To determine the appropriate lag-length the Akaike information criterion (see Green, 2000) was used. In both models five lags was chosen and estimated.

Since a fairly large number of lags are included in the model only data from the 18 counties where there are observations from every year are included. Therefore the total number of observations used is 288 .

Tables 2 and 3 show the results from the tests where the number of trips taken is the dependent variable that is estimation of (11).

Table 2. Results from tests of the effect of vehicle-kilometres on patronage

\begin{tabular}{|l|l|l|}
\hline$F_{\text {hnc }}$ & $\boldsymbol{F}_{\text {hc }}$ & $\boldsymbol{F}_{\text {henc }}$ \\
\hline $2.25^{\star * *}$ & $2.12^{* \star *}$ & 0.68 \\
\hline & & \\
\hline Adj-R ${ }^{2}:$ & 0.67 & \\
\hline
\end{tabular}

$* * *=$ p-value less than $0.001, * *=$ p-value less than $0.01, *=$ p-value less than 0.05

The tests reject the homogenous non-causality hypothesis as well as the homogenous causality hypothesis but not the heterogeneous non-causality hypothesis. The conclusion is therefore that vehicle-kilometres cause patronage in some counties but it is not possible to reject the hypothesis that there are counties where this is not the case. Table 3 shows the results from the individual tests. 
Table 3. Heterogeneous causality tests. From vehicle-kilometres to patronage

\begin{tabular}{|l|cll|c|}
\hline County & & County & \\
\hline Stockholm & 0.86 & Halland & 0.79 \\
\hline Uppland & $5.21^{* * *}$ & Värmland & 0.44 \\
\hline Sörmland & 0.36 & Örebro & 0.88 \\
\hline Östergötland & $6.62^{* * *}$ & Västmanland & 1.48 \\
\hline Jönköping & 0.53 & Dalarna & $14.37^{* * *}$ \\
\hline Kronoberg & 0.1 & Gävleborg & 0.54 \\
\hline Kalmar & 0.25 & Västernorrland & 0.68 \\
\hline Gotland & 0.0074 & Västerbotten & 0.36 \\
\hline Blekinge & 1.01 & Norrbotten & 1.11 \\
\hline
\end{tabular}

$* * *=$ p-value less than $0.001, * *=$ p-value less than $0.01, *=$ p-value less than 0.05

According to the individual tests the hypothesis of no causality is withheld in several counties. This does not mean that there is no causal relationship in all these counties. These results might originate from the fact that there are only 16 usable observations for each county. One of the reasons for using panel-data is to increase the efficiency of the estimates which makes it possible to discover relationships that could not be observed by the study of individuals separately. Of course it might very well be the case that there really is no causal relation in several of the counties.

Tables 4 and 5 show the results from the tests using vehicle-kilometres as the dependent variable that is estimation of (12).

Table 4. Results from tests of the effect of patronage on vehicle-kilometres

\begin{tabular}{|c|c|c|}
\hline$F_{\text {hnc }}$ & $F_{\text {hc }}$ & $F_{\text {henc }}$ \\
\hline $1.59^{*}$ & $1.48^{*}$ & 0.68 \\
\hline & & \\
\hline Adj-R ${ }^{2}:$ & 0.98 & \\
\hline
\end{tabular}

$* * *=$ p-value less than $0.001, * *=$ p-value less than $0.01, *=p$-value less than 0.05

As above the homogenous non-causality hypothesis as well as the homogenous causality hypothesis is rejected. The heterogeneous non-causality hypothesis could not be rejected. The conclusion is therefore that the number of trips made causes the supply of vehicle-kilometres in some counties but it is not possible to reject the hypothesis that there are counties where this is not the case.

Table 5 shows the tests for the individual counties. 
Table 5. Heterogeneous causality tests. From patronage to vehicle-kilometres

\begin{tabular}{|c|c|c|c|}
\hline County & & County & \\
\hline Stockholm & $9.54^{* * *}$ & Halland & 0.24 \\
\hline Uppland & $4.2^{\star \star}$ & Värmland & 0.98 \\
\hline Sörmland & 0.092 & Örebro & 0.11 \\
\hline Östergötland & 0.8 & Västmanland & 0.42 \\
\hline Jönköping & $2.65^{\star}$ & Dalarna & 0.13 \\
\hline Kronoberg & 0.47 & Gävleborg & 0.17 \\
\hline Kalmar & 0.045 & Västernorrland & 0.2 \\
\hline Gotland & 0.0043 & Västerbotten & 1.22 \\
\hline Blekinge & 0.041 & Norrbotten & $7.33^{\star \star \star}$ \\
\hline
\end{tabular}

In this case the hypothesis of no causal effect can only be rejected for four counties. Again, this does not necessarily mean that patronage does not cause vehicle-kilometres in all the other counties. The small amount of observations for each county could account for the results in some counties.

\section{CONCLUDING DISCUSSION}

When the effect of vehicle-kilometres on patronage is considered, the results are that the supply of public transport measured by vehicle-kilometres (granger) cause demand. This effect is county-specific but there are counties where this effect is not present.

The lack of significant relationship in a large number of counties might (besides the small number of observations from each county) be due to a large proportion of captive riders in the system. If the level of service is low most of the travellers with the possibility to choose another mode of transport have already stopped using public transport. If the service-level is decreased further, which has been the case in most counties during the observed period (see table 1), it does not affect patronage. The existing passengers are still unable to change mode of transport. On the other hand it is possible that it takes a large increase in the service level to regain the passengers lost earlier. They might have bought a car and changed their travel behaviour in a number of ways.

Regarding the opposite relationship, the results show that the number of trips made does (granger) cause vehicle-kilometres. As in the first case there are counties where the effect is not present. Where the effect is present it varies between counties.

In this case, the lack of significant effects in several counties might be explained by the need to withhold a minimum level of service on low-density relations. Patronage has been declining during the observed period (see table 1) and it is reasonable to believe that vehiclekilometres provided are decreased when patronage falls but only to a certain minimum level. The decision-makers are often reluctant to leave a relation where service has previously been provided completely without service in the future. The political price of such decisions is often high. Hence, if the level of service is low further decrease in patronage might not cause a decrease in vehicle-kilometres provided. 
One possible reason for the estimated effect to differ between counties is the absence of other possible explaining variables in the models. If equation (6) and (7) are true the absence of these other variables included when estimating equation (11) and (12) could explain why the measured effects differ.

In summation, there seems to be a feedback relationship between trips made and vehiclekilometres. This relationship should be considered and included in the model when demand models are estimated. If this is not done the results might be biased and the value of them could be questioned.

The further exploration of the relationship between travel demand and supply, as well as the formulation and estimation of a demand model where it is included, is important work left for the future.

It is also of interest to study if a large proportion of existing public transport passengers are, in fact, captive riders as suggested above.

Another important field of research left for the future is the question of the political rigidities in the decision-making process. Do these rigidities exist, and if so, how do they affect possibilities of running an efficient public transport system?

\section{REFERENCES}

Baltiagi, B. (2001). Econometric Analysis of Panel Data. John Wiley \& Sons LTD, New York.

Banerjee, A. (1999). Panel Data Unit Roots and Cointegration: An Overview. Oxford Bulletin of Economics and Statistics, 607-629.

Dargay, J. and M. Hanly (2002). The Demand for Local Bus Services in England. Journal of Transport Economics and Policy, 36, 73-91.

Granger, C. (1969). Investigating Causal Relations by Econometric Models and CrossSpectral Methods. Econometrica, 37 (3), 424-438.

Green, W. (2000). Econometric Analysis. Prentice-Hall, London

Holmgren, J. (2001). The demand for public transportation. Masters Thesis, Linköping University.

Hurlin, C. and B. Venet (2001). Granger Causality Tests in Panel Data Models with Fixed Coefficients. http://www.core.ucl.ac.be/EC2/EC2papers/hurlin.pdf.

Jansson, K. and B. Wallin (1991). Deregulation of public transport in Sweden. Journal of Transport Economics and Policy, 25, 97-107.

Levin, A. and C.-F. Lin (1993). Unit Root Tests in Panel Data: New Results. University of California at San Diego. Discussion Paper no. 93-56.

Mackie, J. (1974). The Cement of Universe. Clarendon Press, Oxford.

Maddala, G.S. and S. Wu (1999). A Comparative Study of Unit Root Tests with Panel Data and a New Simple Test. Oxford Bulletin of Economics and Statistics, 631-652. 
Pedroni, P. (1999). Critical values for cointegration tests in heterogeneous panels with multiple regressors. Oxford Bulletin of Economics and Statistics, 61, 653-670.

Sims, C. (1972). Money, Income and Causality. American Economic Review, 62, 540-552.

SLTF (2002), Public Transport in Sweden-co-ordination and competition.

http://www.sltf.se/fileupload/pubdok/Public\%20transport\%20in\%20Sweden_2002_06 10.pdf.

Webster, F.V. and P.H. Bly (1980). The demand for public transport. Report of an international collaborative study, Transport and Road Research Laboratory. Crowthorne, Berks. 